\title{
Real Time MATLAB Interface for Speed Control of Induction Motor Drive using dsPIC 30F4011
}

\author{
R. Arulmozhiyal \\ Senior Lecturer, \\ Sona College of \\ Technology, Salem, \\ TamilNadu, India
}

\author{
K.Baskaran \\ Assistant Professor, \\ Government College \\ of Technology, \\ Coimbatore, \\ Tamil Nadu, India
}

\author{
N.Devarajan \\ Assistant Professor, \\ Government College \\ of Technology, \\ Coimbatore, \\ Tamil Nadu, India
}

\author{
J.Kanagaraj \\ Assisatant Professor, \\ PSG College of \\ Technology, \\ Coimbatore, \\ Tamil Nadu, India
}

\begin{abstract}
This paper presents design and implementation of Real time MATLAB Interface for speed control of induction motor drive using dsPIC 30F4011. In recent years, the field oriented control of induction motor drive is widely used in high performance drive system. It is due to its unique characteristics like high efficiency, good power factor and extremely rugged .This scheme leads to be able to adjust the speed of the motor by control the frequency and amplitude of the stator voltage, the ratio of stator voltage to frequency should be kept constant
\end{abstract}

Keywords: Fuzzy logic control (FLC), Membership Function, PIC digital signal microcontroller Induction motor, Intelligent Power Module.

\section{INTRODUCTION}

In recent years, speed control of induction motor drive is widely used in high performance drive system , because of its advantages like high efficiency, very simple, extremely rugged, good power factor and it does not require starting motor. Induction motors are used in many applications such as HVAC, Industrial drives control, automotive control, etc... In recent years there has been a great demand in industry for adjustable speed drives [1].

Recently, Fuzzy logic control has found many applications in the past decade. Fuzzy Logic, deals with problems that have vagueness, uncertainty and use membership functions with values varying between 0 and 1[2]. This means that if the a reliable expert knowledge is not available or if the controlled system is too complex to derive the required decision rules, development of a fuzzy logic controller become time consuming and tedious or sometimes impossible. In the case that the expert knowledge is available, fine-tuning of the controller might be time consuming as well $[3,4]$. Real time implementation of MATLAB Interface for speed control of induction motor drive using dsPIC $30 \mathrm{~F} 4011$ as quite new. [57]. The aim of this paper is that it shows the dynamics response of speed with design the fuzzy logic controller to control a speed of Induction motor. This paper presents design and real time implementation of MATLAB Interface for speed control of induction motor drive using dsPIC 30F4011.

\section{PROPOSED SPEED CONTROL SYSTEM}

Figure-1 shows the block diagram the proposed system. From the induction motor sense the speed using Quadature Encoder pulse (QEP) sensor, then Speed is given back to the Intelligent power Module(IPM), From the IPM, speed converted into the voltage in analog form. Through the PIC controller analog form of the voltage converted in digital form. Digital form input to the MATLab Work. In the MATLab work we design the fuzzy logic control, from that we obtain the controlled output given to the dsPIC controller. Depends upon the controlled output, the controller produce the SVPWM signals, that signals feed back into the gate drive of the IGBT of Intelligent Power Module. Inverter output from the intelligent power module is given to the input of the induction motor.

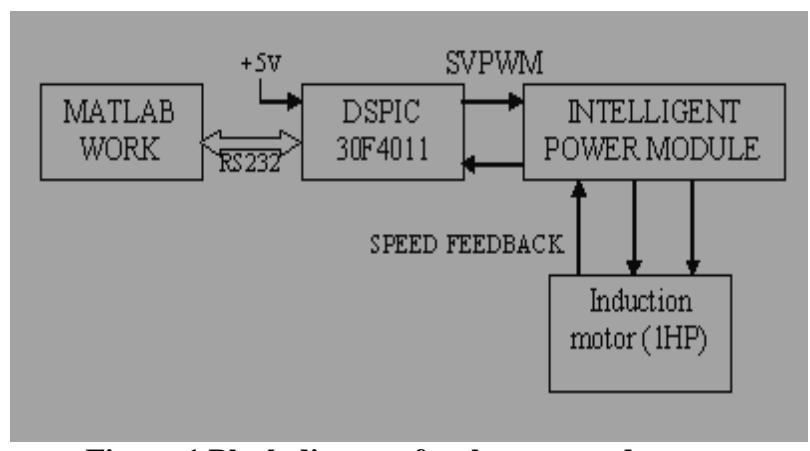

Figure-1 Block diagram for the proposed system

Figure-2 show the MATLAB work, where Query instrument is Digital signal PIC controller (dsPIC 30F 4011). The speed error e and the change of speed error ce are processed inputs through the fuzzy logic controller whose output is the controlled voltage to dsPIC controller. The controlled output voltage from the fuzzy logic controller is processed by PIC controller to produce a control frequency and Amplitude. This control frequency adjusts the V/f of SVPWM such that the desired speed of the motor can be obtained[8-11].

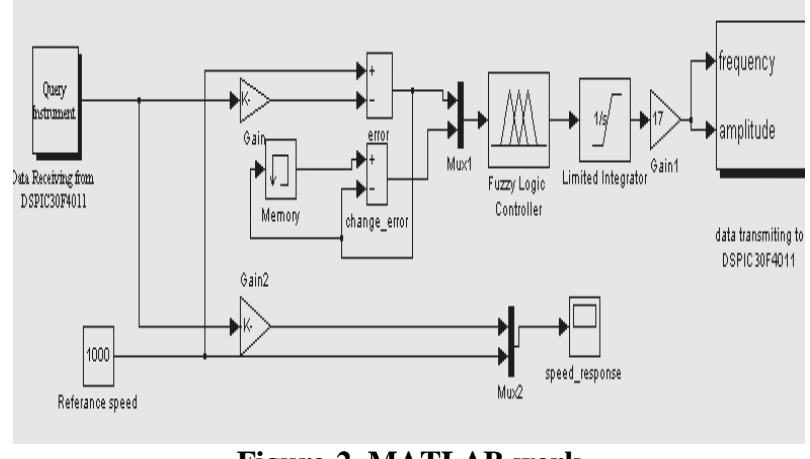

Figure-2 MATLAB work

\section{FUZZY LOGIC CONTROL}

The process of fuzzy logic controller design includes the following steps. (i)Fuzzification: process of representing the inputs as suitable linguistic variable. (ii) decision Making: appropriate control action to carried out. It is based on the knowledge base and rule base. Knowledge base and rule base are the details about the linguistic variables and control rules 
(iii) Defuzzification: Process of converting fuzzified output into crisp value. The inputs to the FLC are error (e) and change in error (ce). The output is the voltage of the switching signal.

The universe of discourse of all the variables, covering the whole region, is expressed in per unit values. All the MFs are asymmetrical because near the origin, the signals require more precision. There are seven MFs for e and ce signal, whereas there are seven MFs for the output. All the MFs are symmetrical for positive and negative values of the variables. Table 1 shows the corresponding rule table for the speed controller. The top row and left column of the matrix indicate the fuzzy sets of the variables e and ce, respectively, and the MFs of the output variable du are shown in the body of the matrix. There may be $7 * 7=49$ possible rules in the matrix.

Mamdani type controller is chosen for this application and the basic rule of this type of controller is

IF ce is PS AND e is NM THEN du is NS. Membership functions are associated with each lable as shown in Figure. 3(a)-(c)

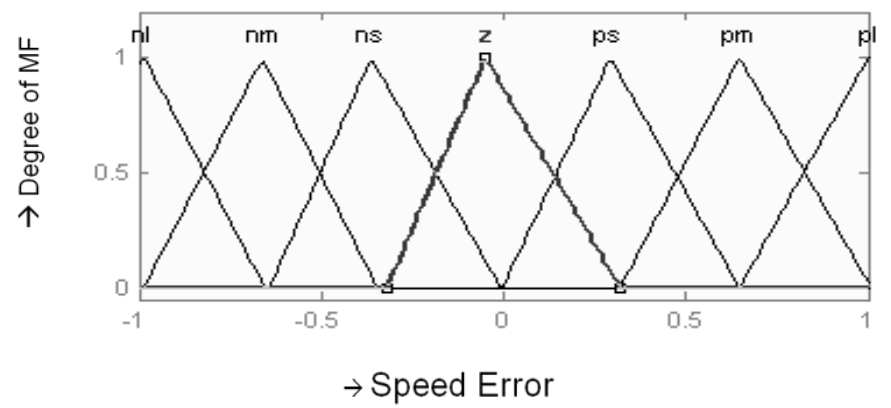

(a) MF for speed error

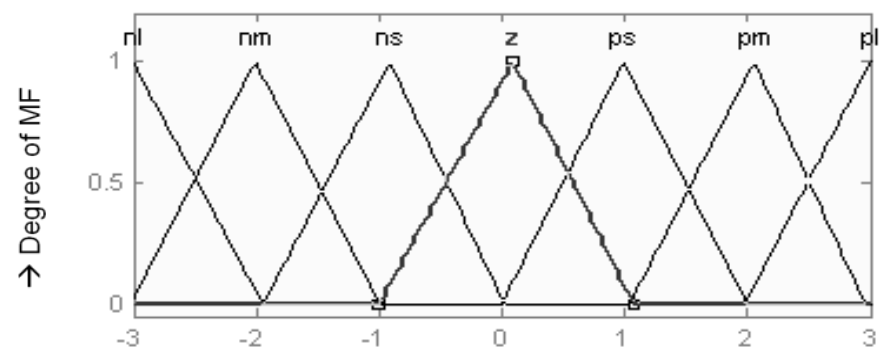

$\rightarrow$ Change in speed error

(b) MF for change in speed error

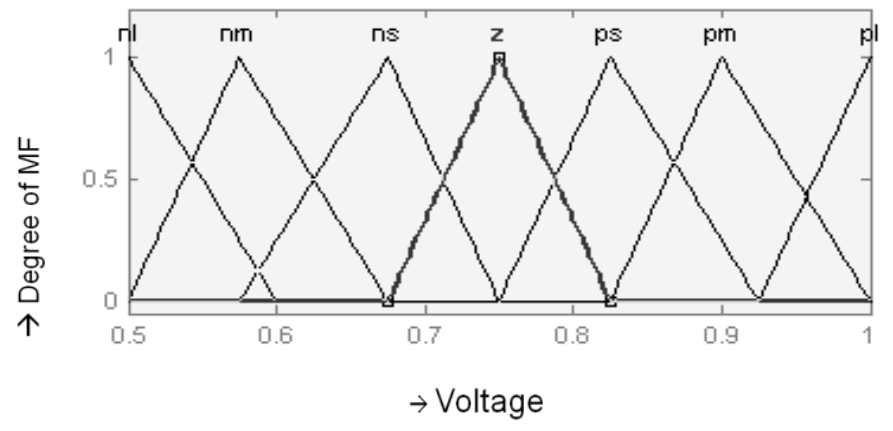

(c) MF for voltage

Figure 3- Membership functions for input and output variables
Table 1. Rule base Speed control

\begin{tabular}{|c|c|c|c|c|c|c|c|c|}
\hline & $\mathrm{e}$ & \multirow[t]{2}{*}{$\mathrm{nl}$} & \multirow[t]{2}{*}{$\mathrm{nm}$} & \multirow[t]{2}{*}{ ns } & \multirow[t]{2}{*}{ Z } & \multirow[t]{2}{*}{ ps } & \multirow[t]{2}{*}{$\mathrm{pm}$} & \multirow[t]{2}{*}{$\mathrm{pl}$} \\
\hline ce & $\mathrm{u}$ & & & & & & & \\
\hline $\mathrm{nl}$ & & $\mathrm{nl}$ & $\mathrm{nl}$ & $\mathrm{nl}$ & $\mathrm{nl}$ & $\mathrm{nm}$ & $\mathrm{ns}$ & $\mathrm{Z}$ \\
\hline $\mathrm{nm}$ & & $\mathrm{nl}$ & nl & $\mathrm{nl}$ & $\mathrm{nm}$ & $\mathrm{ns}$ & Z & $\mathrm{ps}$ \\
\hline $\mathrm{ns}$ & & $\mathrm{nl}$ & $\mathrm{nl}$ & $\mathrm{nm}$ & ns & Z & ps & $\mathrm{pm}$ \\
\hline $\mathrm{Z}$ & & $\mathrm{nl}$ & $\mathrm{nm}$ & ns & Z & ps & $\mathrm{pm}$ & $\mathrm{pl}$ \\
\hline ps & & $\mathrm{nm}$ & ns & $\mathrm{Z}$ & ps & $\mathrm{pm}$ & pl & $\mathrm{pl}$ \\
\hline $\mathrm{pm}$ & & ns & $\mathrm{Z}$ & ps & $\mathrm{pm}$ & $\mathrm{pl}$ & $\mathrm{pl}$ & $\mathrm{pl}$ \\
\hline$\overline{\mathrm{pl}}$ & & Z & ps & $\mathrm{pm}$ & $\mathrm{pl}$ & $\mathrm{pl}$ & $\mathrm{pl}$ & $\mathrm{pl}$ \\
\hline
\end{tabular}

\section{SPACE VECTOR PULSE WIDTH MODULATION}

The basic power circuit topology of a three-phase voltage source inverter supplying a star connected three-phase load is given in Figure 4. The power circuit contains in general six semiconductor switches such as MOSFETs, IGBTs, BJTs etc with antiparallel diodes for protection. The two power switch of one leg is complimentary in operation with a small dead band between the switching of two devices. Switching operation of the inverter yield in total 8 output vectors with 6 being active or non zero and two zero vectors. The six active vectors are labeled as $\mathrm{V}_{1}, \mathrm{~V}_{2}, \mathrm{~V}_{3}, \mathrm{~V}_{4}, \mathrm{~V}_{5}, \mathrm{~V}_{6}$ and the two zero vectors are labeled as $\mathrm{V}_{\mathrm{o}}$ and $\mathrm{V}_{7}$.



Figure 4 Power Circuit topology of a three-phase VSI.

If these 8 voltage vectors are converted to 2 axis, it can be plotted as shown in Figure 5. The tips of the 6 non zero vectors, when cornered form a regular hexagon with the two zero vectors lying at the origin.

The $\mathrm{V}_{\text {ref }}$ in $\alpha-\beta$ plane rotates circularly, so that the output voltage will be sinusoidal. Since the voltage source inverter can have 8 states, Vref can only be synthesized by using 8 voltage vectors. There can be infinite ways to synthesize the input reference but the most simple is by using the two neighboring active vectors and a zero vector. In other words it can be said that the inverter is switched in such a way that the two neighboring output voltage is generated. If the direction of rotation of the reference vector is assumed as anticlockwise then the vector to the right is designated with suffix ' $a$ ' and the vector lying on the left of the reference is denoted with suffix ' $b$ '. The inverter switching is done is such a way that one state (say 001) remains for some time (say $\mathrm{T}_{\mathrm{a}}$ ) and is followed by another state (say 011) for some time (say $\mathrm{T}_{\mathrm{b}}$ ). 


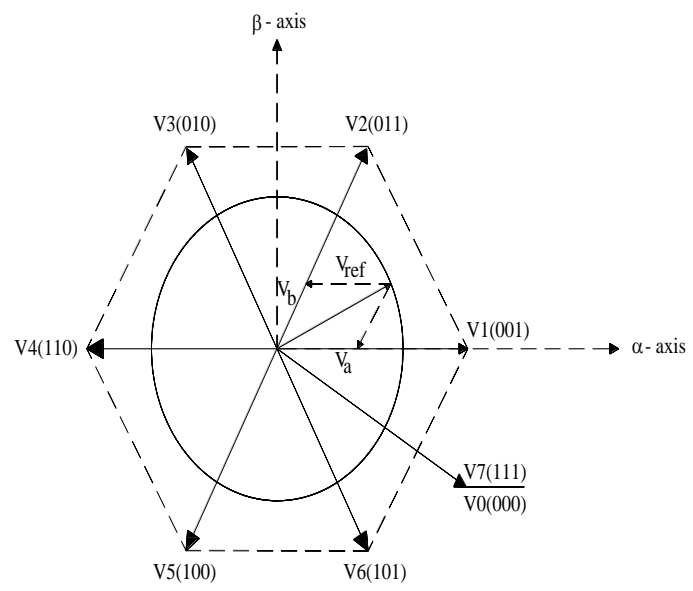

Figure 5 Space voltage vectors of a three-phase VSI.

The remaining time out of one switching period $\left(\mathrm{T}_{\mathrm{s}}\right)$ is filled with the application of vector $\mathrm{V}_{\mathrm{o}}$ for time $\mathrm{T}_{0} / 2$ and vector $\mathrm{V}_{7}$ for time $\mathrm{T}_{0} / 2$. Thus a symmetrical space vector modulation is obtained. If $\mathrm{V}_{\text {ref }}$ is in $1^{\text {st }}$ sector, then, where,

$\mathrm{T}_{\mathrm{a}} \quad$ - Switching time for non zero vector (V1) in $1^{\text {st }}$ sector

$\mathrm{T}_{\mathrm{b}} \quad$ - Switching time for non zero vector (V2) in $1^{\text {st }}$ sector

$\mathrm{T}_{0} \quad$ - Zero vector switching time $\left(\mathrm{V}_{\mathrm{o}}, \mathrm{V}_{7}\right)$ in $1^{\text {st }}$ sector

$\mathrm{T}_{\mathrm{s}} \quad$ - Total switching time period

$$
\begin{aligned}
& V_{r e f}=\bar{V}_{a}+\bar{V}_{b} \\
& \overline{V_{r e f}} \times T_{s}=\overline{V_{1}} \times T_{a}+\overline{V_{2}} \times T_{b}+\overline{V_{o}}\left(V_{7}\right) \times T_{0} \\
& T_{s}=T_{a}+T_{b}+T_{0}
\end{aligned}
$$

The second equation is termed as equal volt-sec. principle. The inverter output voltage $\overline{V_{k}}$ can assume only eight discrete locations in the complex plane, including the zero voltage vectors. The zero voltage vector will be included in the switching sequence to minimize the commutations in the inverter (Turn ON and Turn OFF losses will be less).

One can generate any voltage vector laying inside the hexagon whose corners on the six active switching state vectors $\left(\mathrm{V}_{1}\right.$ to $\mathrm{V}_{6}$ ) in space vector modulation strategy, the inverter out net reference vector $\overline{V_{\text {ref }}}$ can be approximated during a sampling time $\Delta t=1 /\left(2 f_{s}\right)$ by a sequence of 3 space voltage vectors $\mathrm{V}_{\mathrm{a}}, \mathrm{V}_{\mathrm{b}}$ and $\mathrm{V}_{\mathrm{N}}$, where $\mathrm{V}_{\mathrm{a}}$ and $\mathrm{V}_{\mathrm{b}}$ are 2 of the adjacent six active vector $\mathrm{V}_{1} \ldots . \mathrm{V}_{6} \mathrm{~V}_{\mathrm{N}}$ is a zero vector $\mathrm{V}_{\mathrm{o}}$ and $\mathrm{V}_{7}$ chosen in such a way to minimize the commutations in the inverter $f_{s}$ is the switching frequency.

The above time intervals $T_{a}, T_{b}$ and $T_{o}$ during which the switching state vectors $\mathrm{V}_{\mathrm{a}}, \mathrm{V}_{\mathrm{b}}$ and $\mathrm{V}_{\mathrm{N}}$ are applied are derived from the geometry of the hexagon and can be written as the following formulas

$$
\begin{aligned}
& T_{a}=\frac{\sqrt{3}}{\pi} m T_{s}\left[\sin \frac{k \pi}{3} \cos \theta-\cos \frac{k \pi}{3} \sin \theta\right] \\
& T_{b}=\frac{\sqrt{3}}{\pi} m T_{s}\left[\cos \frac{(k-1) \pi}{3} \sin \theta-\sin \frac{(k-1) \pi}{3} \cos \theta\right] \\
& T_{0}=T_{s}-\left(T_{a}+T_{b}\right)
\end{aligned}
$$

where $\theta$ is the angle between $\mathrm{v}_{\mathrm{a}}$ and $\bar{V}_{\text {ref }}$ $\mathrm{m}$ is the modulation index. This is the generic solution for each sector in the plane, $\theta$ always varies in the interval $\left(0-60^{\circ}\right)$. By varying the modulation index $\mathrm{m}$ and $\theta$, the output voltage amplitude and frequency can be varied. Modulation index control the output voltage magnitude and $\theta$ controls the frequency of the output voltage. where,

\section{m - Modulation index \\ $\theta \quad$ - Vector Angle}

When equations for $\mathrm{T}_{\mathrm{a}}, \mathrm{T}_{\mathrm{b}} \& \mathrm{~T}_{\mathrm{o}}$ are implemented in digital signal PIC micro controller, the compare registers value corresponding to $T_{a}, T_{b} \& T_{o}$ have to be calculated and loaded to generate the 6 PWMs for the three phase voltage source inverter. This results in 3 phase voltage output from a voltage inverter using space vector pulse width modulation. This SVPWM is used in vector control implementation when rotating reference frame operation is considered.

\section{5. dSPIC MICROCONTROLLER}

The dsPIC30F is a High Performance Digital Signal Controllers with CPU module has a 16-bit (data) modified Harvard architecture with an enhanced Instruction set, including significant support for DSP. The instruction set includes many addressing modes and was designed for optimum $\mathrm{C}$ complier efficiency.

A. Features

1. High performance modified RISC CPU

2. 48 Kbytes on-chip Flash program space (16K Instruction words)

3. $2 \mathrm{~Kb}$ of on-chip data $\mathrm{RAM}$ and $1 \mathrm{~Kb}$ of nonvolatile data EEPROM

4. $4 \mathrm{MHz}-10 \mathrm{MHz}$ oscillator input with PLL active (4x, 8x, 16 as)

5. $16 \times 16$ - bit working register array

6. Timer module with programmable presale

7. 6-bit Capture input and 16- bit Compare/PWM output functions

8. 2 UART modules with FIFO Buffer

9. 6 PWM output channels

10. Analog-to-Digital Converter (A/D) with $4 \mathrm{~S} / \mathrm{H}$ Inputs

For more about features of aspic refer respective data sheet.

\section{PULSE GENERATION USING dsPIC A. Register Involved:}

I/O Port control registers:

All I/O ports have three registers directly associated with the operation of the port, where ' $\mathrm{x}$ ' is a letter that denotes the particular I/O port. TRISx: Data Direction registers, PORTx: I/O Port registers, LATx: I/O Latch registers. Each I/O pin on the device has an associated bit in the TRIS, PORT and LAT Registers.

Timers:

TMRx: 16-bit timer count register, PRx: 16-bit period register associated with the timer, TxCON: 16-bit control register associated with the timer. Some16-bit timers can be combined to form a 32-bit timer.

Input capture and output compare:

The Input Capture module has multiple operating modes, which are selected via the ICxCON register. The dsPIC30F device may have up to eight output compare channels, designated OC1, OC2, OC3, etc., Each output compare channel can use 
one of two selectable time bases. The time base is selected using the OCTSEL bit $(\mathrm{OCxCON}<3>)$.

Motor control PWM control registers:

The control registers are PTOCN, PTMR, PTPER, PWMCON and PDC.

\section{B. Flow chart:}

A flow chart of the proposed system is shown in Figure 6

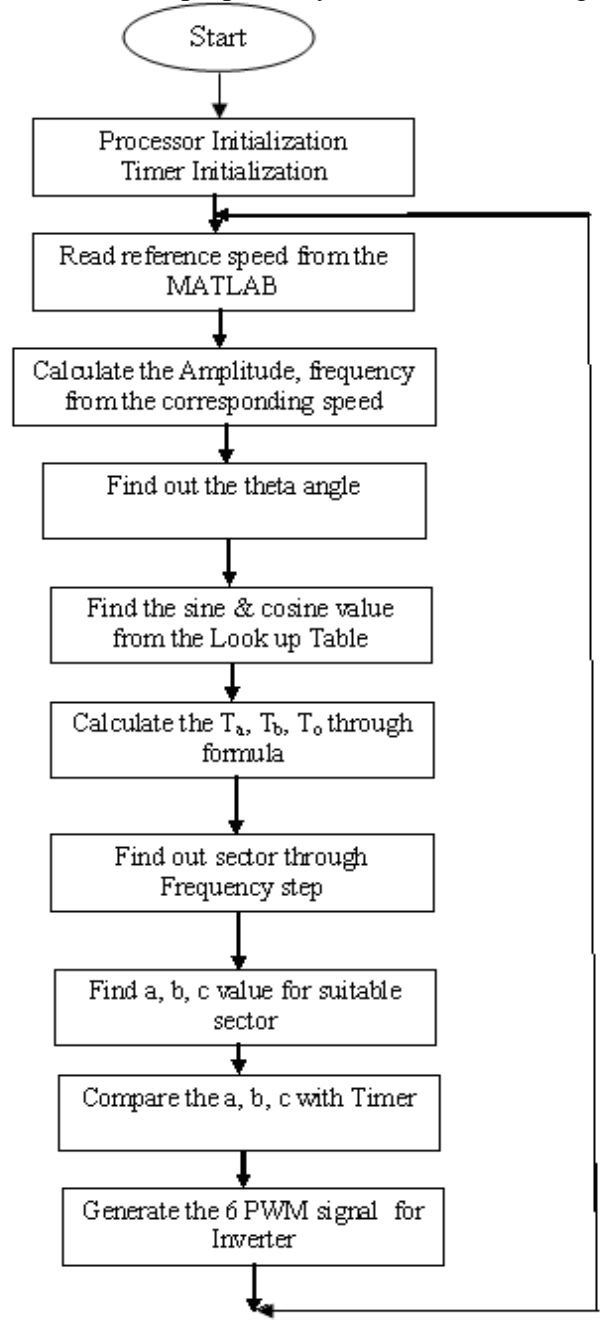

Figure 6 Flowchart

\section{HARDWARE RESULTS}

To evaluate the performance of the system, a series of measurements has been accomplished. Figure.7 as shows hardware setup diagram and DSPIC controller diagram.

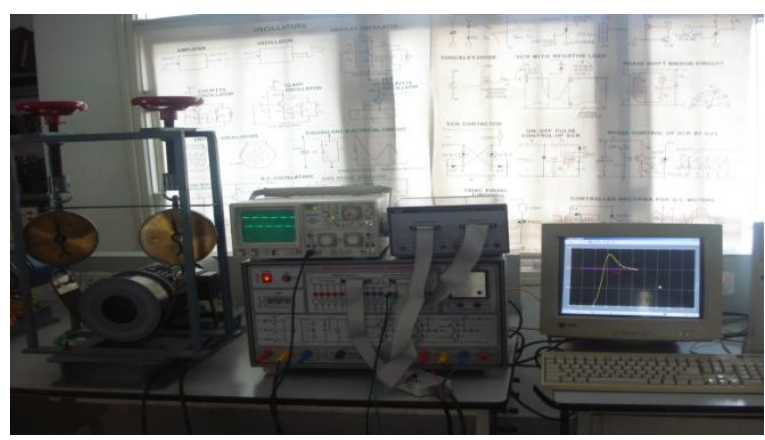

(a) Experimental setup

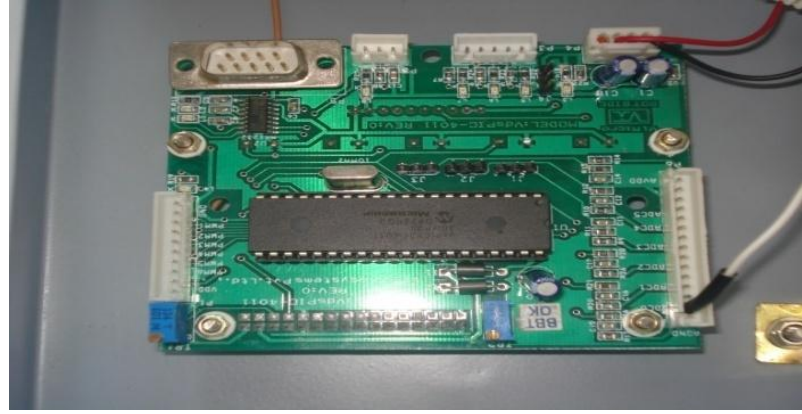

(b) DSPIC controller

Figure 7 Hardware setup

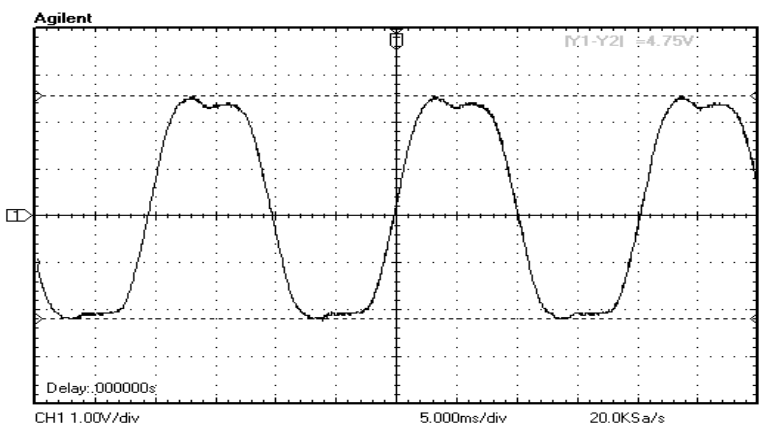

Figure 8 SVPWM

By using the experimental setup we find the following results. Figure 8 shows a Space Vector PWM. Figure. 9(a) and (b) as shown speed response of the fuzzy logic controller with a fuzzy tuning rule based on Reference speed of 1000rpm and 1200 rpm.

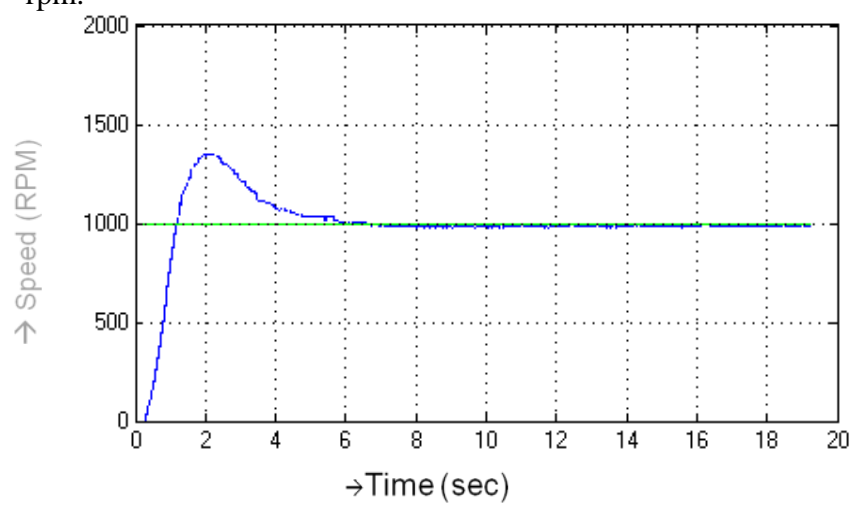

(a) Normal response for 1000 RPM

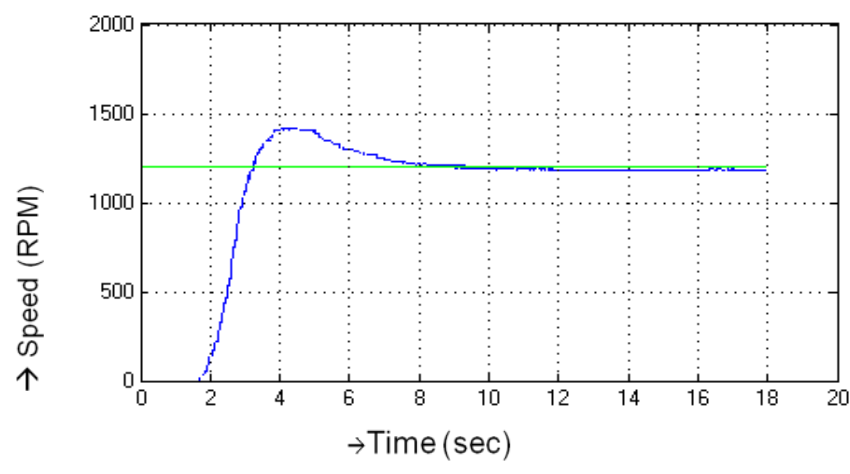

(b) Normal response for 1200 RPM

Figure 9 Normal response of the proposed system 
Figure10 (a) shown step up speed response for 500 to1000 RPM of the proposed system.

Figure10 (b) shown step down speed response for 1000 to 500 RPM of the proposed system.

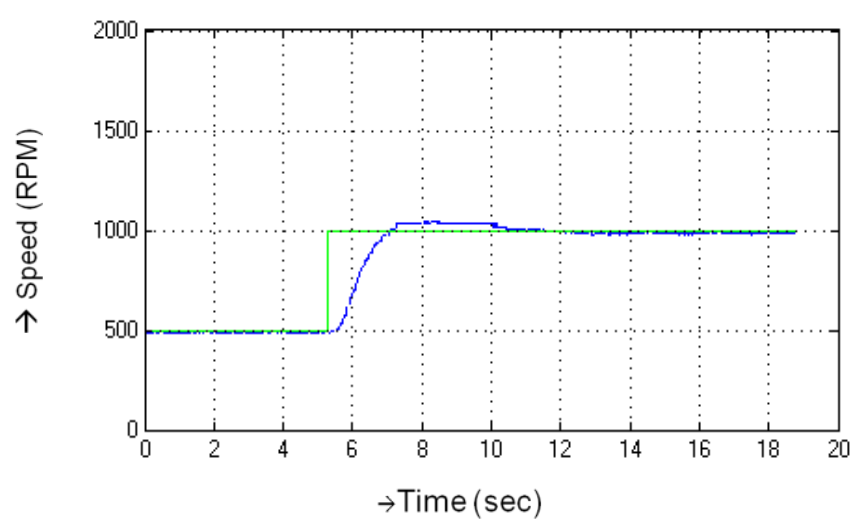

(a) Speed Step up response for 500-1000 RPM

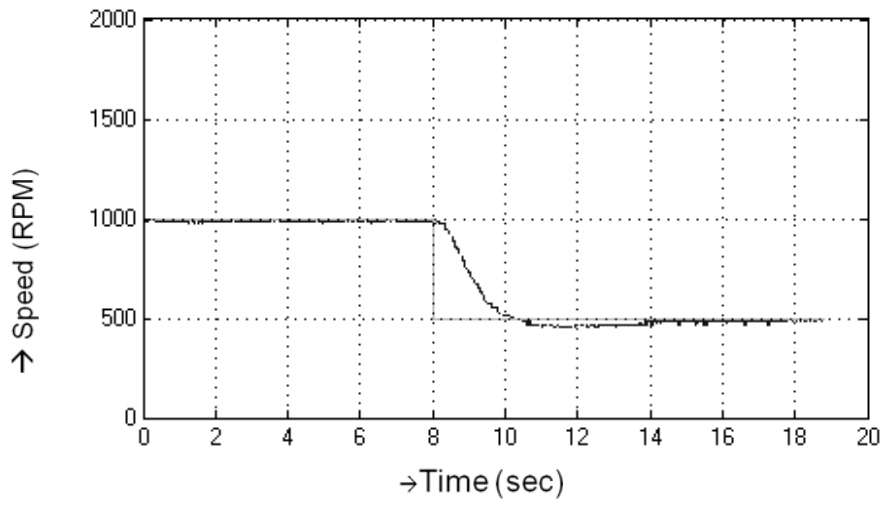

(b) Speed Step down response for 1000-500 RPM

Figure 10 Step response of the proposed system

Figure11 (a) shown step up and down speed response for 1000 to1200 RPM of the proposed system

Figure10 (b) shown step down and up speed response for 1200 to 1000 RPM of the proposed system.

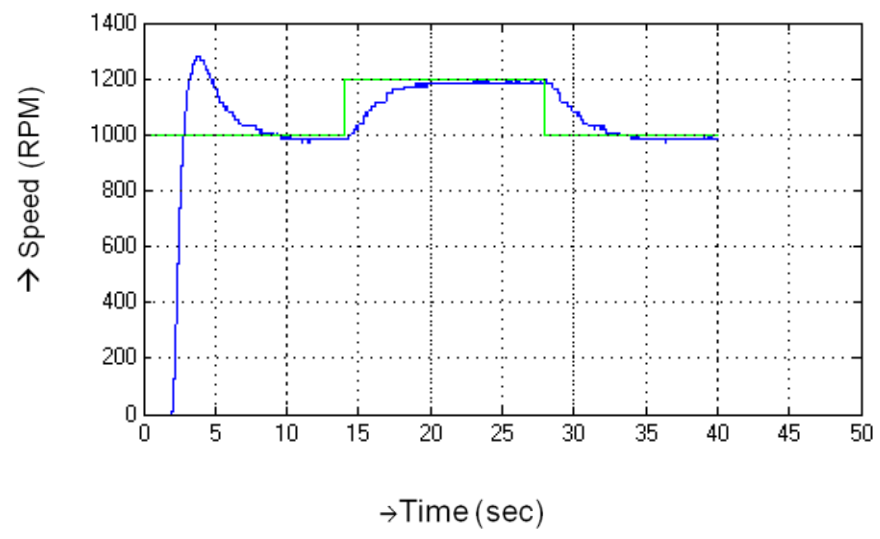

(a) Speed step up and down response for 1000-1200 RPM

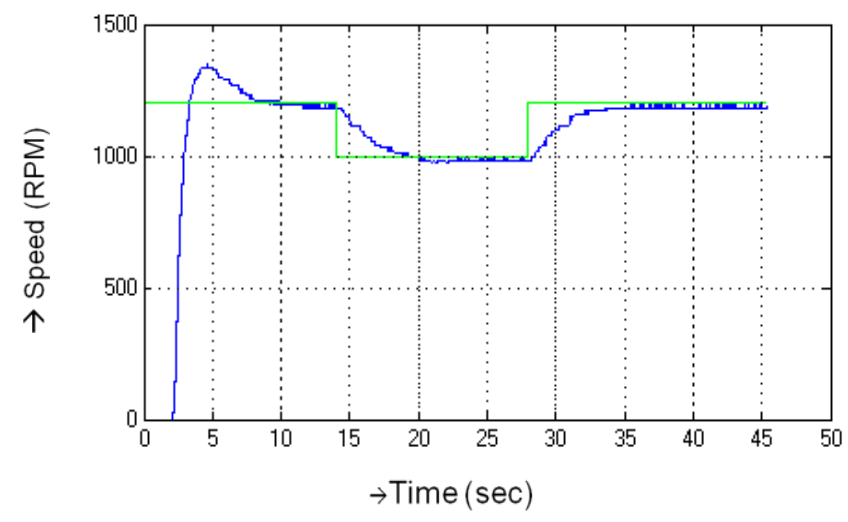

(b) Speed step down and up response for 1000-1200 RPM

Figure 11 Step up and down response of the proposed system

Figure. 12 as shown the stability of speed when load changes at 1000 RPM of the proposed system

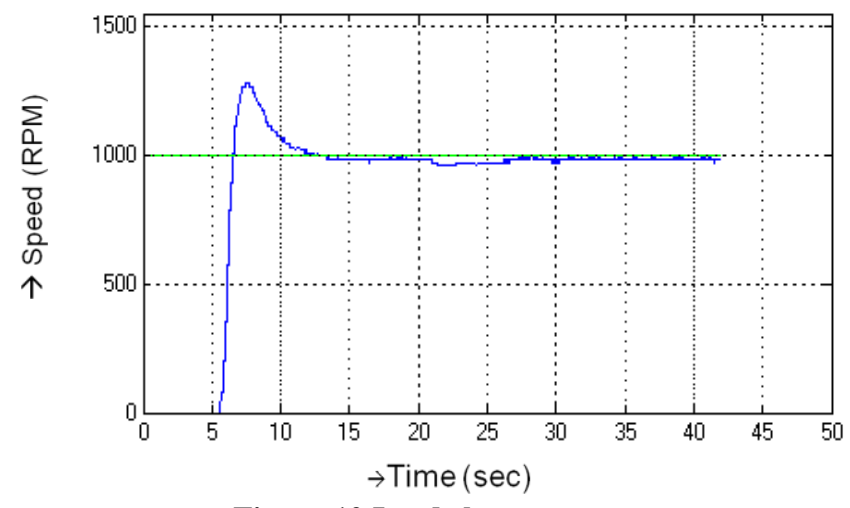

Figure-12 Load change response

\section{CONCLUSION}

This paper presents implementation of Real time MATLAB Interface for speed control of induction motor drive using dsPIC 30F4011. The experimental results are analyzed and, it's found that the speed of the induction motor can be controlled in Normal, step up, step down response.

\section{ACKNOWLEDGMENT}

The authors wish to thank the Management, Principal and the Department of Electrical and Electronics Engineering, Sona College of Technology, Salem-5, TamilNadu who have given facilities to do this research work successfully.

\section{REFERENCES}

[1]. W. Leonhard, Control of Electrical Drives, Springer-Verlag Berlin Heidelberg, New York, Tokyo, 1985.

[2]. Chuen Chien Lee, "Fuzzy Logic in Control Systems: Fuzzy Logic controller -Part1,2” 1990 IEEE.

[3]. R.Arulmozhiyal and K.Baskaran,"A Novel Approach to Induction motor speed control using FPGA",International Journal of Applied Engineering Research, ISSN 0973-4562, Volume 4, Number 1 (2009), pp 1-14.

[4]. R.Arulmozhiyal and K.Baskaran, " Space vector pulse width modulation based speed control of Induction 
motor using Fuzzy PI controller", International Journal of Computer and Electrical Engineering, ISSN 1793-8198, Volume 1, Number 1 (2009), pp 98-103.

[5]. High Performance Digital Signal Controllers "dspic30f Family Reference Manual and data sheet"

[6]. Krishnaram. K, and Jeevananthan. S, (2009), "dsPIC $30 f 4011$ based gating unit for performance enhanced phase controlled rectifier systems", International Conference on Electrical Energy Systems \& Power Electronics in Emerging Economics, Chennai, India, pp.1156-1161.

[7]. Seydi Vakkas Ustan and Metin Demirtas(2009), "Modeling and control of v/f controlled induction motor using genetic-ANFIS algorithm", Energy Conservation and Management, Elsevier publishers,Vol.50, No.3, pp.786-791.

[8]. Alfredo Munoz-Garcia, Thomas A. Lipo, and Donald W. Novotny (1998), “A new induction motor $\mathrm{v} / \mathrm{f}$ control method capable of high performance regulation at low speeds", IEEE Transactions on Industry Applications, Vol. 34, No. 4, pp.813-821.

[9]. Dragan Maksimovic, Regan Zane and Robert Erickson (2004), "Impact of Digital Control in Power Electronics", Proceedings of International Symposium on Power Semiconductor Devices and IC's, Kitakyushu, pp. $13-22$

[10]. Narayanan.G, and Ranganathan.V.T, (1999), "Synchronised PWM strategies based on space vector approach. Part 2: Performance assessment and application to V/f drives", IEEE Proceedings in Electric Power Applications, Vol.146, No.3, pp. 276-281.
[11]. Lazhar Ben-Brahim (1998), "Improvement of the stability of the $\mathrm{v} / \mathrm{f}$ controlled induction motor drive systems", Proceedings of the 24th Annual Conference of the IEEE Industrial Electronics Society, IECON, New Orleans, LA, pp. 859-864.

\section{AUTHORS PROFILE}

R. Arulmozhiyal was born in Chennai, Tamil Nadu, India in 1973. She received the B.E. and M.E. degrees in electrical engineering from the University of the Madras, Anna, India, in 1999 and 2006, respectively. Since 1999, She has been with Department of Electrical and Electronics Engineering, Faculty of Engineering, Sona College of Technology, Tamil Nadu, India where she is currently a Senior Lecturer. Her research interests are in the areas of $\mathrm{AC}$ motor control and $\mathrm{AI}$ Techniques to Solid State Drives. Mrs. Arulmozhiyal is a Member of the IEEE society and life member in ISTE.

K. Baskaran was born in Thanjavur, Tamil Nadu, India, in 1964. He received the B.E. and M.E. degrees in Electrical Engineering from the University of the Annamalai, Bharathiyar, Tamil Nadu, India, in 1985 and 1995, respectively, and the Ph.D. degree in Computer Science engineering from Anna University, Chennai, India, in 2004. Since 1989, he has been with the Department of Electrical and Electronics Engineering, Faculty of Engineering, Government College of Technology, Coimbatore, India, where he is currently an Assistant Professor. His research interests are in the areas of networking and soft computing. Prof. Baskaran is a member of the IEEE . 